\title{
Da variação à revelação nas canções de adoniran barbosa
}

\section{From variation to revelation in the songs of adoniran barbosa}

DOI: $10.46814 /$ lajdv3n3-037

Recebimento dos originais: 01/052021

Aceitação para publicação: 31/06/2021

\section{Vera Lúcia Massoni Xavier da Silva}

Licenciada em Letras

Mestrado e Doutorado em Linguística e Língua Portuguesa pela Unesp de Araraquara

Vínculo atual: Instituto Municipal de Ensino Superior de Catanduva-IMES Catanduva

\section{Carlos Fernandes-Netto}

\section{Licenciado em Letras}

Mestrado e Doutorado em Estudos Literários pela Unesp de Araraquara

Pós-Doutorado pelo Departamento de Teoria Literária do Instituto de Estudos da Linguagem, da

Unicamp

Vínculos atuais: Centro Paula Souza (Faculdade de Tecnologia Nilo De Stéfani-Fatec Jaboticabal;

Faculdade de Tecnologia de Ribeirão Preto-Fatec Ribeirão Preto); Secretaria da Educação de Ribeirão Preto (Escola Municipal Prof. Alfeu Luiz Gasparini)

\section{INTRODUÇÃO}

Nosso interesse pelas canções de Adoniran Barbosa (João Rubinato, Valinhos, SP, 1910 - São Paulo, 1982) surgiu durante as aulas de Sociolinguística, principalmente no que diz respeito ao emprego da variante não padrão nas canções do compositor paulista.

Inquietou-nos, sobremaneira, o comportamento dos alunos de Letras, quando expostos a exemplos de emprego com desvios da língua padrão, uma vez que a grande maioria os considera corruptela, como modo de falar "errado". Quando questionados sobre gostar ou não gostar de Adoniran, a resposta é afirmativa. Daí, a intenção de verificar o que faz com que suas canções sejam apreciadas e, por que não dizer, cantadas por pessoas ditas cultas e comentadas pela crítica literária, como se depreende das palavras de Antonio Candido (2002):

Adoniran Barbosa é um grande compositor e poeta popular, expressivo como poucos [...]. Já tenho lido que ele usa uma língua misturada de italiano e português. Não concordo. Da mistura, que é o sal de nossa terra, Adoniran colheu a flor e produziu uma obra radicalmente brasileira, em que as melhores cadências do samba e da canção, alimentadas inclusive pelo terreno fértil das Escolas, se aliaram com naturalidade às deformações normais de português brasileiro, onde Ernesto vira Arnesto, em cuja casa nós fumo e não encontremo ninguém, exatamente como por todo esse país. [...] (CANDIDO, 2002, p. 211). 


\section{SOCIOLINGUÍSTICA: PRESSUPOSTOS BÁSICOS}

Gnerre (1985, p.6), em sua obra Linguagem, Escrita e Poder, discute a relação entre língua e sociedade, afirmando que "somente uma parte dos integrantes das sociedades tem acesso a uma variedade 'culta' ou 'padrão'".

Pode-se afirmar que língua padrão é a que goza do prestígio das camadas sociais mais elevadas e está associada a um patrimônio cultural e consolidada na escrita. Ora, não são todos os indivíduos da comunidade que têm acesso a essa modalidade. Vale dizer, ainda, que o prestígio de uma língua em detrimento de outra não ocorre, apenas, no interior de uma comunidade, mas se estende ao plano internacional. $\mathrm{O}$ francês, por exemplo, foi durante muito tempo a língua de prestígio; hoje, sabemos que, por razões econômicas, científicas e culturais, o inglês é a língua prestigiada.

Embora se ouça afirmar que o Estado e o poder se apresentam como neutros em relação à língua padrão, isso é pura ilusão, ou, como nas palavras de Bakhtin (1990, p.6), trata-se de "objetivismo abstrato". A sustentação dessa posição embasa-se na concepção de língua como sistema estável e imutável; na consideração de que as leis da língua são apenas linguísticas e que, nas relações linguísticas, não há fatores ideológicos interferindo.

A ideia de Saussure (1973) sobre a língua como social refere-se ao fato de ela ser um sistema convencional adquirido pelos indivíduos de uma sociedade. O que isso quer dizer? É simples: aos falantes não é permitido sair por aí mudando os nomes dos objetos e das coisas do mundo, pois os nomes já estão fixados, por meio de um acordo tácito entre os indivíduos. Ressalte-se: toda nova criação (neologismo) - lembre-se, a propósito, da genialidade de Guimarães Rosa - deve adequar-se à estrutura da língua. Assim, uma palavra como, por exemplo, ZXPTKY não se constituirá em signo de nenhuma língua.

Embora Saussure (1973) reconheça a importância de se levarem em consideração fenômenos externos à estrutura da língua, tais como natureza etnológica, histórica e política, sua ênfase centra-se na estrutura linguística interna da língua. Com isso, há uma nova oposição: linguística interna e linguística externa. Entendam-se como elementos externos fatores como sexo, faixa etária, nível socioeconômico, nível cultural e contexto situacional, que interferem no uso da língua. Aqui, já se verifica a relação entre língua e sociedade.

Quanto à ideia de relação entre língua e sociedade, observamos autores de destaque, como Mikhail Bakhtin (1990), que, em sua obra Marxismo e Filosofia da Linguagem, posiciona-se contrário à concepção de Saussure no tocante à não necessidade de conhecimento de fatores externos para se conhecer a estrutura da língua. Sua tônica, portanto, centra-se na noção de comunicação social. 
A verdadeira substância da língua não é constituída por um sistema abstrato de formas lingüísticas, nem pela enunciação monológica isolada, nem pelo ato psicofisiológico de sua produção, mas pelo fenômeno social da interação verbal realizada através da enunciação ou das enunciações. A interação verbal constitui assim a realidade fundamental da língua. (BAKHTIN, 1990, p. 123, grifo nosso).

Benveniste (2008) afirma que indivíduo e sociedade se determinam pela e na língua. $\mathrm{Na}$ concepção do linguista, a língua é manifestação concreta da linguagem. Assim, língua e sociedade só podem ser concebidas mutuamente.

Para esse autor, a língua é um instrumento de comunicação comum a todos os membros da sociedade e, como tal, constitui-se no interpretante da sociedade. O que isso quer dizer? É simples: pode-se afirmar que o vocabulário de uma língua se constitui fonte inesgotável para o estudo da sociedade.

Nessa perspectiva, devemos considerar as afirmações de Bourdieu (1977):

\begin{abstract}
A linguagem não é usada somente para veicular informações, isto é, a função referencial denotativa da linguagem não é senão uma entre outras; entre estas ocupa uma posição central a função de comunicar ao ouvinte a posição que o falante ocupa de fato ou acha que ocupa na sociedade em que vive. As pessoas falam para serem "ouvidas", às vezes para serem respeitadas e também para exercer uma influência no ambiente em que realizam os atos lingüísticos. $\mathrm{O}$ poder da palavra é o poder de mobilizar a autoridade acumulada pelo falante e concentrá-la num ato lingüístico. (BOURDIEU, 1977, apud GNERRE, 1985, p. 32).
\end{abstract}

Como se pode depreender, todo ato de linguagem é direcionado a um ouvinte e com uma intenção: agir sobre o outro. Nesse caso, ao falar, o sujeito coloca em cena seu ponto de vista sobre o mundo, ao mesmo tempo em que revela o lugar que ocupa na sociedade: juiz, advogado, professor, mãe, dentre outros. Todo ato de linguagem, então, leva em conta as relações entre falante e ouvinte.

Tarallo (1990, p. 6) afirma que não há comunidade linguística homogênea, pois em cada situação comunicativa o emprego da língua é diversificado e heterogêneo. Isso poderia levar-nos a concluir que a heterogeneidade caracterizará um caos; no entanto, devemos salientar que toda essa diversidade deve ser sistematizada, pois, se assim não o fosse, não haveria compreensão entre os falantes de uma comunidade. Para isso, há a necessidade de se considerarem as variantes existentes no contexto social não como exceções ou variações de livre escolha do falante, mas como partes do conhecimento que o falante possui de sua língua.

\title{
3 SOCIOLINGUÍSTICA: OBJETO
}

A Sociolinguística tem como objeto o estudo da língua falada, observada, descrita e analisada em seu contexto social, em situações reais de uso. Para tanto, parte da comunicação entre pessoas que interagem por meio da linguagem, se relacionam e cuja comunicação é regida por um 
conjunto de regras que governam o uso da língua, dependentes, dentre outros fatores, da situação (formal ou informal) em que se encontram os falantes.

Para Gnerre (1985):

As regras que governam a produção apropriada dos atos de linguagem levam em conta as relações sociais entre o falante e o ouvinte. Todo ser humano tem que agir verbalmente de acordo com tais regras, isto é, tem que "saber":

a) quando pode falar e quando não pode;

b) que tipo de conteúdos referenciais lhe são consentidos;

c) que tipo de variedade lingüística é oportuno que seja usada. [...] nem todos os integrantes de uma sociedade têm acesso a todas as variedades e muito menos a todos os conteúdos referenciais. Somente uma parte dos integrantes das sociedades complexas, por exemplo, tem acesso a uma variedade "culta" ou "padrão", considerada geralmente "a língua", e associada tipicamente a conteúdos de prestígio. (GNERRE, 1985, p.6).

No que diz respeito às regras citadas por Gnerre (1985), devemos considerar que, a depender da situação formal ou informal, ao ouvinte a que se destina o ato de fala do sujeito produtor, deve-se empregar uma ou outra variante. Dessa maneira, um professor, em sala de aula ou em uma conferência, fará uso da língua padrão. Analogamente, não se vai a uma instituição católica para fazer apologia ao aborto, ou, de modo geral, funcionários de repartições públicas não se dirigem a pessoas ocupantes de cargos elevados na hierarquia oficial tratando-as por "você", pois esse pronome é indicador de tratamento familiar.

A língua é um objeto histórico e se transforma no tempo. Assim, o português que falamos hoje é diferente do português falado no passado. Drummond (ANDRADE, 1983) foi consciente dessa variação temporal, quando escreveu "Antigamente":

ACONTECIA o indivíduo apanhar constipação; ficando perrengue, mandava o próprio chamar o doutor e, depois, ir à botica para aviar a receita, de cápsulas ou pílulas fedorentas. Doença nefasta era a phtysica, feia era o gálico. Antigamente, os sobrados tinham assombrações, os meninos lombrigas, asthma os gatos, os homens portavam ceroulas, botinas e capa-de-goma, a casimira tinha de ser superior e mesmo X.P.T.O. London, não havia fotógrafos, mas retratistas, e os cristãos não morriam: descansavam.

MAS TUDO ISSO era antigamente, isto é, outrora. (ANDRADE, 1983, p.1320-1321).

A leitura do fragmento acima permite visualizar uma série de termos que entraram em desuso ("constipação", "perrengue”, "botica”, “aviar", "phtysica”, "asthma”, “ceroulas”, "capa-de-goma”, "retratistas"), revelando a variação temporal de termos empregados no Brasil de antigamente. Tais expressões são denominadas arcaísmos.

Os exemplos acima são característicos da variação histórica ou diacrônica, pois têm a ver com o passar do tempo. É bom lembrar que, para o reconhecimento de uma variante histórica, é fundamental que se considerem, pelo menos, dois estados sucessivos da língua, ressaltando-se que as duas variantes, a substituta e a substituída, coexistem num mesmo plano temporal. É pela escrita, que 
tem, dentre as suas funções, a de preservar o passado, que reconhecemos o processo de variação histórica.

Os fatores constituintes da diversidade linguística não são decorrentes apenas da influência do tempo, mas também do espaço geográfico, importante para a configuração de variantes. Nesse caso, estamos falando das variantes geográficas ou espaciais, também denominadas diatópicas.

O Brasil se destaca pela sua grande extensão espacial. Assim, constitui-se um engano acreditar na existência de unidade linguística no país.Vale dizer, ainda, que a língua portuguesa falada em Portugal é bem diferente da falada aqui no Brasil. Essas diferenças ocorrem nos diferentes níveis da estrutura da língua (fonético, sintático, lexical e de uso).

O falar nordestino, por exemplo, é marcado pela abertura das vogais; os gaúchos não neutralizam o o e o e átonos finais; na região do São Francisco, dama tem o significado de meretriz; no sertão baiano, a oclusiva alveolar surda (/t/), após semivogal anterior, palatiza-se na africada /t $\mathrm{f} /$, como, por exemplo, em oitcho.

Além das variações históricas e geográficas, ocorrem variações sociais, resultantes da tendência a maior semelhança entre os atos de fala proferidos pelos membros de um mesmo setor sociocultural da comunidade. Cada grupo social possui determinadas expressões, entonações e especificidades que propiciam diferentes falares nos distintos grupos sociais. Claro está que o grau de educação, o nível socioeconômico, o sexo e a faixa etária dos indivíduos também determinam setores distintos de atividade verbal.

Resta abordarmos a variação estilística, resultante de acomodações que o falante faz de sua fala em relação às diferentes situações comunicativas em que se encontra. Nessa perspectiva, há inúmeras variações, já que, a todo momento, defrontamo-nos com situações comunicativas distintas. Por essa razão, pode-se afirmar que os falantes de mesma classe social ou de mesmo nível intelectual não usam a língua sempre da mesma maneira. Assim, um médico que se encontre em um clube com amigos de diferentes formações profissionais, conversando sobre banalidades, não usará, todo o tempo, expressões restritas à profissão médica.

\section{VARIANTE PADRÃO E VARIANTE NÃO PADRÃO}

A variante padrão caracteriza-se por ser socialmente mais prestigiada e mais valorizada. Seu uso se dá, principalmente, em situações formais, situações de interação determinadas, tais como conferências, congressos, solenidades. Seu emprego depende, ainda, do tipo de assunto tratado e da relação entre os interlocutores, isto é, considera-se o fato de os envolvidos no ato comunicativo pertencerem ao mesmo grupo social ou à mesma profissão. 
A variante padrão (norma culta) resulta de uma atitude social em relação à língua. Vamos entender bem isso. A língua, em seu sentido mais amplo, é a mesma para o médico, para o técnico de informática, para o professor, para o faxineiro, mas ela é usada de formas diferentes. Dessa maneira, um falante culto vai selecionar, dentre as várias possibilidades de uso da língua, aquela considerada "correta". Vale dizer que o modo considerado "correto" costuma ser vinculado às camadas sociais mais elevadas.

A fixação da variante padrão, usada na literatura, nos meios de comunicação, nas leis, nos decretos do governo, na escola, onde é ensinada, tal como explicada pela gramática e definida nos dicionários, representa um padrão ideal de homogeneidade em meio à existência de inúmeras possibilidades de uso da língua.

A variante não padrão é adotada pelas camadas sociais de menor prestígio na sociedade. Esse português não padrão apresenta variantes em consonância com as diferentes regiões geográficas, classes sociais, faixas etárias e níveis de escolarização. Em princípio, pode-se afirmar que a variante não padrão é falada pelas pessoas mais pobres e menos escolarizadas.

Em termos educacionais, a variante não padrão é considerada "errada", e, frequentemente, o aluno que dela faz uso é desprestigiado no ambiente escolar, é considerado deficiente linguístico. Assim, como se já não bastassem as demais formas de exclusão social (econômica, tecnológica, étnica, entre outras), surge mais uma: a exclusão linguística.

Vale dizer, ainda, que as variantes são estabelecidas por critérios metodológicos e que, em certo momento, elas convivem entre si. É claro que será alçada a padrão a variante aceita e usada pelo poder e pelas classes sociais mais elevadas.

\section{PROCEDIMENTOS ENUNCIATIVOS}

Fiorin (1996, p. 36) afirma que enunciação enunciada se caracteriza por um conjunto de marcas referentes à enunciação, enquanto o enunciado enunciado é a sequência desprovida de marcas da enunciação.

Ao evidenciar os conceitos de "debreagem" e "embreagem", termos que designam os mecanismos de instauração de pessoa, espaço e tempo no enunciado, o autor esclarece que há dois tipos de debreagem: a enunciativa, em que se instalam no texto o eu/tu, o espaço da enunciação (aqui) e o tempo (agora), e a debreagem enunciva, que se constitui por instaurar no enunciado um não eu (ele), o espaço não aqui (algures) e o tempo não agora (então).

Em relação aos sistemas temporais, afirma o autor que há o sistema enunciativo, cujos tempos verbais são instaurados a partir do momento da enunciação (agora/hoje), e o enuncivo, evidenciado pela ordenação temporal a partir de momentos de referência passados, instaurados no texto. 


\title{
6 O CORPUS EM ANÁLISE
}

Adoniran, em suas canções, fazendo uso da debreagem enunciativa, potencializa a expressividade da interação verbal, conforme se observa abaixo:

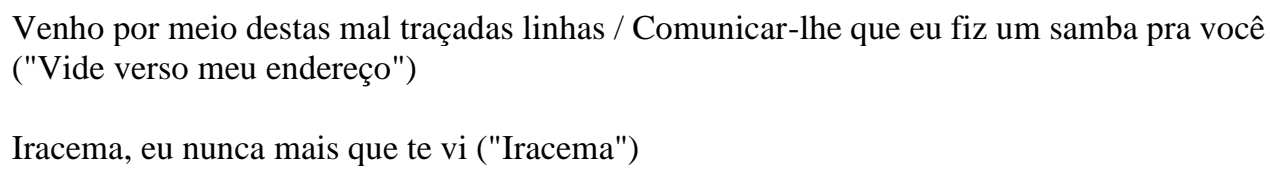

O poeta joga com os sistemas temporais e pessoais, pois o emprego da $1^{\mathrm{a}}$ e $3^{\mathrm{a}}$ pessoas e do ontem e hoje são marcas de muitas de suas composições.

\author{
Iracema, eu sempre dizia \\ Cuidado ao travessar essas ruas \\ Eu falava, mas você não me escutava não \\ Iracema, você travessou contra mão \\ E hoje ela vive lá no céu \\ E ela vive bem juntinho de nosso Senhor \\ De lembranças guardo somente suas meias e seus sapatos \\ Iracema, eu perdi o seu retrato.
}

(“Iracema”)

Ao instaurar, no texto, seu interlocutor Iracema, o poeta emprega tempos verbais do sistema enuncivo, perfeito e imperfeito, cujo efeito de sentido é propiciar ao leitor um quadro descritivo caracterizador da morte de Iracema.

A aproximação de passado e presente e a instauração da $3^{a}$ pessoa podem ser entendidas como um jogo discursivo, em que o "eu" se afasta do texto, instaura um "ela", de modo a aproximar o transcendente do mundo real.

Para a construção de um quadro cotidiano, o poeta lança mão do "ontem" e do "hoje", como na letra da canção "Saudosa Maloca". Vale dizer que essa canção assinala, também, o processo de urbanização da cidade de São Paulo, em que os velhos palacetes foram demolidos para dar lugar aos altos edifícios. É São Paulo se modernizando e sendo cantado nos versos do poeta, porém na voz dos excluídos.

\footnotetext{
Peguemos todas nossas coisas

E fumos pro meio da rua

Apreciar a demolição

Que tristeza que nós sentia

Cada tauba que caía

Doía no coração

E hoje nós pega a paia nas grama do jardim

E pra esquecer nós cantemos assim
}

("Saudosa maloca") 
Os recursos empregados pelo poeta não se esgotam com o jogo de pessoas e de tempos verbais; ao contrário, a sua genialidade maior está na perfeita adequação da fala em consonância com o interlocutor. Nessa perspectiva, observamos emprego da língua padrão e da língua não padrão num jogo discursivo ímpar. Em "Existência", contrariando o consenso de poeta que mistura italiano e português, destacam-se o emprego de metáforas ("Ronda íngreme dos sonhos / Que acordados se revelam / São fantasmas não risonhos"), o vocabulário culto (íngreme, escalpelam, loquaz) e a citação de poeta inglês, como se constata abaixo:

\section{Ronda íngreme dos sonhos Que acordados se revelam São fantasmas não risonhos Que ferem e se escalpelam. Eu sou de humilde contato Tímido, nem sou loquaz, Byron disse: estou aqui, Estou comigo, estou feliz!}

("Existência")

Outro exemplo de adequação, não só ao destinatário, mas também ao propósito desencadeador da situação enunciativa, pode ser encontrado no modo entre respeitoso, submisso e protestador dos versos da canção "Despejo na favela" ("Não tem nada não, seu doutor", "Em qualquer canto me arrumo", "Mas essa gente aí, hein? / Como é que faz?").

Em "Vide verso meu endereço", verifica-se perfeita adequação de uso da língua aos interlocutores, Gervásio e Dr. José Aparecido. Na fala dirigida a Gervásio, há o emprego da língua não padrão, como se constata no exemplo:

\section{Seu Gervásio,}

Se Dr. José Aparecido aparecer por aqui

Cê dá esse bilhete a ele.

Pode lê, num tem segredo nenhum.

Pode lê, Seu Gervásio.

("Vide verso meu endereço)

Contrariamente à variante utilizada no pedido a Gervásio, na carta ao Dr. José há o emprego da língua padrão, constatada, por exemplo, na regência do pronome "lhe" pelo verbo "comunicar":

\footnotetext{
Venho por meio destas mal traçadas linhas

Comunicar-lhe que eu fiz um samba pra você

No qual eu quero expressar toda a minha gratidão

E agradecer de coração

Por tudo que você me fez
} 
O jogo de emprego de língua padrão e língua não padrão é bastante evidente em "As mariposa", pois, no enunciado enunciado, diálogo simulado entre a lâmpada e as mariposas, há o emprego da língua padrão, como no caso do vocábulo culto "oscular", que, em contraste com a variante não padrão, resulta em efeito cômico: "Permita-me oscular a sua face". Do emprego da língua não padrão, destacam-se: desvios de concordância nominal e verbal (“As mariposa [...] fica, elas roda"); dissimilação, como em "lâmpida"; rotacismo, observado em "vorta"; palatização, constatada em "muié”; dissimilação e inserção de fonema em "dispois".

\section{CONCLUSÃO}

As canções de Adoniran corroboram o consenso de "bom falante": aquele que é capaz de adequar seus atos linguísticos ao interlocutor e à situação comunicativa em que se encontra; o falante que faz usos de diferentes variações, buscando a verdadeira interação pela linguagem. Como se lê nas palavras de Antonio Candido (2002), o poeta da mistura de nossa terra colheu a flor e produziu uma obra radicalmente brasileira. Os recursos da língua - metáforas, personificações, jogos discursivos, pessoais e verbais - aliaram-se, com naturalidade, às variações padrão e não padrão do português brasileiro.

Vale dizer que o emprego da língua não padrão, muitas vezes, foge do lugar comum, pois é evidente, em algumas das canções de Adoniran Barbosa, a marca de pessoa e número assinalada na forma verbal, como se observa em "nós fumos" e "não encontremos".

De maneira singular, o poeta seleciona o emprego da língua padrão, normalmente, para falar de sentimentos íntimos, pessoais, individuais. Diferentemente, para dizer as coisas do cotidiano, situações específicas de um interlocutor ou interlocutores integrantes de grupos sociais não prestigiados, é empregada a língua não padrão. Ressalte-se, porém, que a representação estilística dessa variante ocorre de modo a jamais depreciar os sujeitos envolvidos na interação verbal; ao contrário, eles têm sua realidade humana revelada pelos recursos formais empregados.

Conclui-se que, nas letras das canções de Adoniran, a adequação à inerência das situações vividas pelas camadas populares é responsável pelo poder de desvendamento do real. 


\section{REFERÊNCIAS}

ANDRADE, C. D. de. Poesia e prosa. Rio de Janeiro: Nova Aguilar, 1983.

BAGNO, M. Preconceito linguístico. São Paulo: Loyola, 2002.

BAKHTIN, M. Marxismo e filosofia da linguagem. São Paulo: Hucitec, 1990.

BENVENISTE, E. Problemas de linguística geral I. 5.ed. Campinas: Pontes, 2008.

CANDIDO, A. Adoniran Barbosa. In: . Textos de intervenção. Seleção, apresentação e notas de Vinicius Dantas. São Paulo: Duas Cidades; Ed. 34, 2002.p.211-213.

FIORIN, J. L. As astúcias da enunciação. São Paulo: Ática, 1996.

GNERRE, M. Linguagem, escrita e poder. São Paulo: Martins Fontes, 1985.

SAUSSURE, F. Curso de linguística geral. São Paulo: Cultrix, 1973.

TARALLO, F. A pesquisa sociolinguística. São Paulo: Ática, 1990. 